\title{
Early detection of chronic obstructive pulmonary disease (COPD): the role of spirometry as a diagnostic tool in primary care
}

\section{Onno CP van Schayck, Anthony D'Urzo, Giovanni Invernizzi, Miguel Román, Björn Ställberg, Christopher Urbina}

\begin{abstract}
Chronic obstructive pulmonary disease (COPD) is common and often undiagnosed in its early stages, especially in smokers, who are also most at risk. Patients can develop severe or very severe disease before they consult a physician. It is therefore important to identify patients at-risk of COPD and check their lung function regularly since early stage disease is often asymptomatic or mistaken for asthma. Primary care physicians are often the first health care providers to encounter patients with COPD in the early stages, and their role in early detection and treatment process is pivotal.
\end{abstract}

Spirometry is a cheap, simple and reliable method for the early detection and monitoring of COPD patients, and for establishing a differential diagnosis. Spirometry gives immediate results and communicating the results to smokers has been shown to motivate them to quit. Early diagnosis and appropriate therapy can positively influence disease course, slowing progression, relieving symptoms and reducing the incidence of acute 'flares', or exacerbations.
Chronic obstructive pulmonary disease (COPD) is a serious multicomponent disease that involves airway obstruction, airway inflammation, airway structural changes, mucociliary dysfunction, and a systemic component. ${ }^{1-3}$ The effects seen outside the lungs include systemic inflammation, weight loss and other nutritional problems, and skeletal muscle dysfunction. $^{3}$

Primary care physicians represent both the first port of call for most COPD patients and these patients' best hope of early and optimal intervention. As a result of an evidence-based review, we evaluate the role of spirometry in the early detection and optimal management of these patients.

\section{The burden of COPD}

The World Health Organisation (WHO) has estimated that 600 million people worldwide suffer from COPD,${ }^{4}$ and ranks COPD as the fifth leading cause of death in Europe, exceeded only by heart disease, stroke, lung cancer and lower respiratory tract infections. ${ }^{5}$ COPD is the fourth leading cause of death in the USA. Furthermore, it is estimated that COPD will become the third leading cause of death worldwide by 2020, with only heart disease and cerebrovascular disease accounting for more deaths. ${ }^{6}$ COPD is already the twelfth leading cause of disability and is predicted to become the fifth leading cause of disability worldwide by $2020{ }^{6}$

COPD also has a high economic impact on healthcare systems and society. For instance, in the USA primary care physician office visits contribute significantly to the estimated $\$ 18$ billion annual cost of the disease. ${ }^{7}$ In 2002, estimates of indirect costs such as time off work and lost productivity added up to $\$ 14.1$ billion, making a total cost to society of around $\$ 32.1$ billion. $^{8}$ As the US population ages, the prevalence of COPD is expected to increase, and all associated costs will rise accordingly. ${ }^{9}$ These figures and trends likely to be mirrored in other countries worldwide.

Clearly, the condition is under diagnosed and constitutes a significant burden to physicians, patients, health service providers and society as a whole.

\section{Disease Characteristics}

The Global Initiative for Chronic Obstructive Lung Disease (GOLD) guidelines, which have been developed in collaboration with the National Heart, Lung and Blood Institute and the World Health Organisation, define COPD as a condition involving progressive and not fully reversible airflow obstruction, associated with an abnormal inflammatory response to inhaled irritants. ${ }^{1}$ For many years previously, definitions of COPD have typically described it as a mix of chronic bronchitis (a clinical term) and emphysema (a pathological term).

Chronic bronchitis is defined as productive cough for at least three months per year for at least two consecutive years, ${ }^{1}$ the underlying cause being mucus hypersecretion. ${ }^{2}$ However, chronic cough and phlegm alone are not necessarily indicative of COPD; there is also impaired airflow due to airway narrowing and obstruction. Emphysema is characterised by alveolar destruction and permanent enlargement. Lung elasticity is gradually lost causing breathing difficulties, and there is also compromised gas exchange due to tissue damage. ${ }^{1}$

\section{Recognising COPD}

\section{Presentation}

Symptoms of COPD (shortness of breath, difficulty breathing, cough and sputum production) reflect the relative contributions of its various pathophysiological components. COPD patients may be asymptomatic or show increasingly severe symptoms, including heart failure in extreme cases.

Acute exacerbations of COPD, accompanied by increased symptoms and worsening lung function, are a common occurrence, particularly in some patients in the advanced stages of the disease, as the combination of compromised lung function, tissue damage and impaired mucociliary clearance predisposes to bacterial and other infections. Acute exacerbations
Onno CP van Schayck Universiteit Maastricht, Maastricht

The Netherlands

\section{Anthony D'Urzo}

Primary Care Lung Clinic, Toronto, Canada

Giovanni Invernizzi Respiratory Unit - SIMG (Italian College of GPs)

\section{Miguel Román}

Centro de Salud, Son Pisá, Palma Mallorca

Björn Ställberg

Vardcentralen, SE-619 33

Trosa, Sweden

\section{Christopher Urbina}

Project Director, HETC

University of New

Mexico, USA

on behalf of the Primary Care Respiratory Working Group

Correspondence to: Prof. Onno van Schayck Universiteit Maastricht, Research Institute Captizi PO Box 616, Maastricht 6200MD, The Netherlands

Email:

o.vanschayck@extra.unim aas.nl

Date submitted: 14/08/03 Date Accepted: 02//09/03

Prim Care Resp J 2003; 12(3):90-93 
Fig 1. Comparison of $\mathrm{FEV}_{1}$ curves from normal subjects and patients with COPD

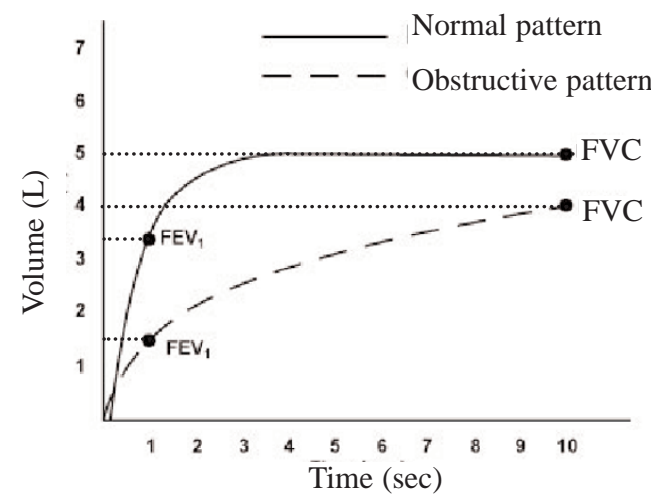

$\mathrm{FEV}_{1}=$ Forced expiratory volume in 1 second; FVC $=$ Forced vital capacity may also occur in response to environmental irritants like airborne pollution, and even to ambient air temperature. ${ }^{10}$

All such exacerbations are a common contributor to COPD-related morbidity and mortality, and occur with increasing frequency as the illness progresses. In addition, acute exacerbations may be prolonged and have an adverse effect on the patient's quality of life. ${ }^{11}$

\section{Early signs may be missed}

In its early stages COPD is sometimes missed, as COPD patients learn to limit their physical activities to escape the gradually emerging dyspnoea on exertion. One recent study found undiagnosed airflow obstruction to be more common than physiciandiagnosed COPD and asthma combined. ${ }^{12}$ Although it is generally agreed that spirometry is essential for confirmation of COPD diagnosis, ${ }^{1}$ it is not always routinely used for early detection of the condition in at-risk patients seen in community practice.

\section{COPD or asthma?}

Since family physicians see many patients with COPD or asthma, and these diseases have overlapping symptomatologies, differential diagnosis can be challenging. However, accurate diagnosis is important because the two conditions require different therapeutic strategies. Wrongly diagnosed COPD is still being treated too often as poorly-responsive asthma. ${ }^{2}$ Such inappropriate treatment is very likely to have a negative effect on outcome for these patients.

\section{Patients at risk of COPD}

A diagnosis of COPD should be suspected in patients who:

- are current or past regular smokers

- have recurrent or chronic respiratory symptoms, including cough or breathlessness during exercise

- have a family history of lung disease

- show other characteristics, including occupational exposure to respiratory irritants, frequent respiratory infections in childhood or passive exposure to tobacco smoke.

\section{Spirometry - what is it and how can it help?}

Spirometry is a simple, non-invasive test that allows an objective assessment of lung function by measuring the volume of air expelled from fully inflated lungs over time. The two key parameters determined by spirometry are:

- FVC, (forced vital capacity) which is the total volume of air forcibly exhaled, and represents a measure of lung capacity

- $\mathrm{FEV}_{1}$, (forced expiratory volume) which is the volume of air forcibly exhaled in the first second, and is a measure of airway patency and lung elasticity.

The ratio of these two measures is used to assess the degree of a patient's airflow obstruction. Depending on age, individuals with normal lung function have an $\mathrm{FEV}_{1} / \mathrm{FVC}$ of between $75 \%$ and $85 \% .{ }^{9}$ In patients with COPD, this ratio is $<70 \%$. $\mathrm{FEV}_{1}$ values are used to establish disease stage. Spirometry traces illustrating how $\mathrm{FEV}_{1}$ values differ between normal subjects and patients with COPD are shown in Figure 1.

\section{Spirometry allows staging of COPD}

GOLD guidelines propose a pragmatic system of staging COPD based on $\mathrm{FEV}_{1}$ values after the patient has taken a bronchodilator, as follows: ${ }^{1}$

- Stage 0 , at risk

- Normal spirometry with chronic symptoms of cough and sputum production

Stage I, mild COPD

- $\mathrm{FEV}_{1}<80 \%$ of the predicted value based on the patient's age, gender and height

- $\mathrm{FEV}_{1}$ to $\mathrm{FVC}$ ratio of $<70 \%$

- Chronic symptoms may or may not be present

- Stage II, moderate COPD

- $\mathrm{FEV}_{1}<80 \%$ but $>50 \%$ of predicted value

- $\mathrm{FEV}_{1}$ to $\mathrm{FVC}$ ratio of $<70 \%$

- Chronic symptoms may or may not be present

- Stage III, severe COPD

- $\mathrm{FEV}_{1}<50 \%$ but $>30 \%$ of predicted value

- $\mathrm{FEV}_{1}$ to $\mathrm{FVC}$ ratio of $<70 \%$

- Chronic symptoms may or may not be present

- Stage IV, very severe COPD

- $\mathrm{FEV}_{1}<30 \%$ of predicted value or $\mathrm{FEV}_{1}$ $<50 \%$ of predicted value plus chronic respiratory failure

- $\mathrm{FEV}_{1}$ to $\mathrm{FVC}$ ratio of $<70 \%$

Spirometry allows early detection

In the early stage COPD, airflow obstruction can be present in the absence of symptoms and patients may be quite unaware that their lung function is not normal. Moreover, in smokers, predictive symptoms such as cough and sputum production are frequently attributed by both patients and physicians simply to the common effects of tobacco inhalation, thus masking any underlying chronic pathology. Help is therefore not routinely sought, or offered, until COPD is well advanced and lung function has deteriorated by $50 \%$ or more (i.e. severe or very severe disease). ${ }^{13}$

If COPD is suspected or likely, spirometry should be 
used to confirm the diagnosis so appropriate management can be initiated (Figure 2). Early identification of COPD is important as the disease is progressive, so steps to prevent or slow down further deterioration need to be taken as soon as possible. Most cases of COPD are due to smoking, and we agree with recent recommendations that physicians should perform an office spirometry test on all their patients over 45 years old who smoke or have recently quit smoking in order to detect COPD. ${ }^{14}$ Office spirometry fulfils all the accepted criteria usually applied to screening tests, being simple and cheap to do, and highly reproducible for an individual patient. $^{9}$

\section{Spirometry can provide an incentive for smokers to quit}

Several studies have shown that if smokers are made aware that their lung function is impaired, they are more likely to quit. ${ }^{15-18}$ Spirometry is a simple way of assessing lung function that gives immediate results which can be communicated to patients, and discussed with them. Research has shown that in smokers susceptible to the development of COPD, quitting does not produce recovery of lost lung function, but subsequent decline with age reverts to a normal rate as shown in Figure $3 .{ }^{19}$

\section{Spirometry can aid differential diagnosis}

When taken in the context of a patient's medical history, including risk factors, spirometry may help physicians to differentiate between COPD and asthma. ${ }^{20} \mathrm{~A}$ proposed algorithm showing how spirometry would fit into this process is shown in Figure 2.

\section{What to look out for with Spirometry}

Although spirometry is an easy-to-use, reliable test when used correctly, physicians need to be aware of some factors they should consider before introducing it into routine clinical use. ${ }^{21}$ These include:

- Appropriate training - all practice staff should be aware of the correct way to use the equipment.

- Quality assurance - regular performance monitoring and feedback is needed to maintain consistent results between practitioners.

- Regular calibration and maintenance of the equipment.

The National Lung Health Education Program (NLHEP) produces a freely-available guide to the use of spirometry in primary care. ${ }^{22}$

\section{The merits of early treatment}

Mild COPD may be asymptomatic and even for symptomatic early-stage disease, current management is often confined to lifestyle advice, such as smoking cessation. While such advice is undoubtedly sound and necessary, physician perceptions of COPD as an untreatable condition may result in patients not receiving optimal therapy.

Traditionally, guidelines for treatment of COPD advocate a 'stepwise' treatment algorithm. For

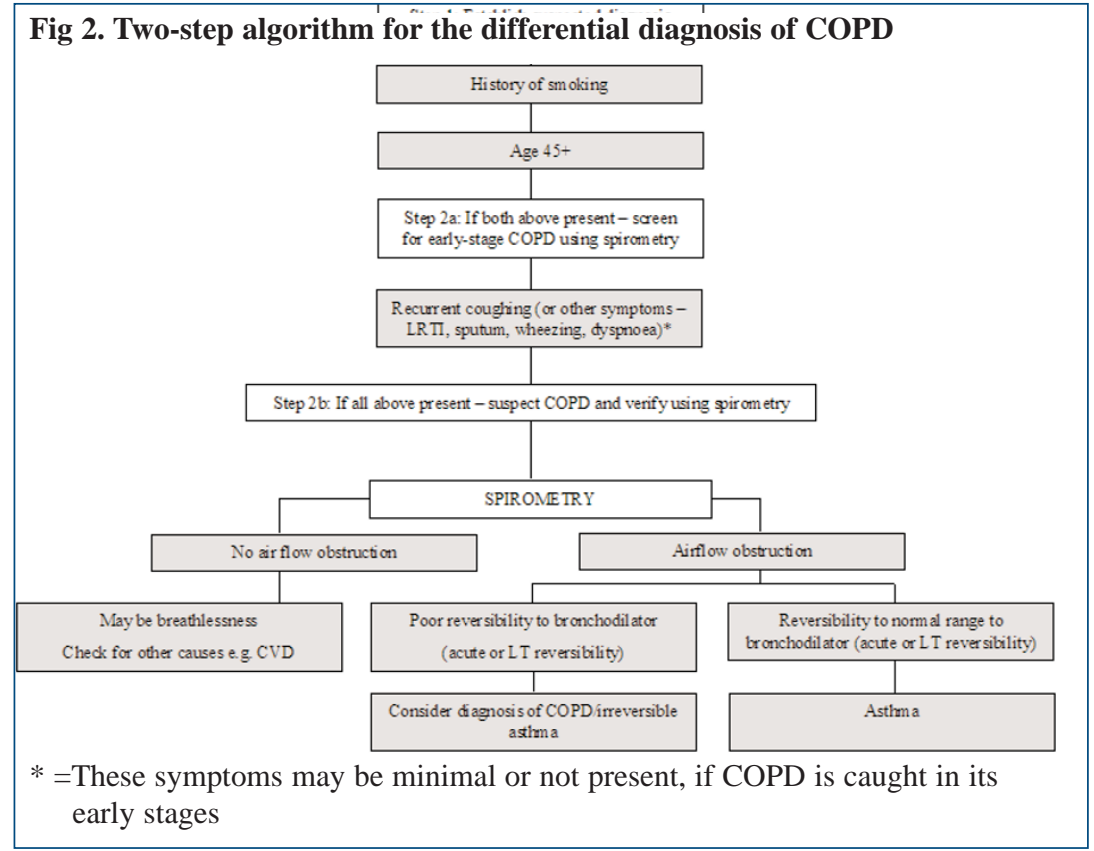

Fig 3. FEV1 decline with age amongst smokers is slowed after smoking cessation (from Fletcher C \& Peto R BMJ 1977; 1:1645-8, with permission)

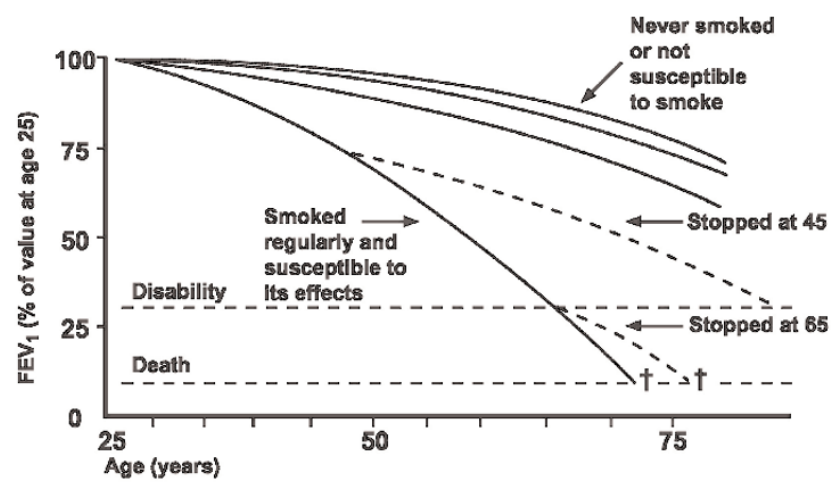

$\dagger=$ Death, the underlying cause of which is irreversible chronic obstructive lung disease, whether the immediate cause of death is respiratory failure, pneumonia, cor pulmonale, or aggravation of other heart disease by respiratory insufficiency.

instance, recent advice published by GOLD recommends: ${ }^{1}$

- Avoidance of risk factors for all at-risk individuals and patients with any stage COPD.

- Addition of a short-acting bronchodilator as needed for mild through severe and very severe stages of disease.

- Addition of regular treatment with one or more long-acting bronchodilators, and rehabilitation, for all patients with moderate through severe and very severe disease.

- Addition of inhaled glucocorticosteroids if there are frequent exacerbations of severe or very severe disease.

- Long-term oxygen therapy in patients with very severe disease / in chronic respiratory failure (with consideration of surgery).

Several studies have shown a beneficial effect of drug therapy, in particular combinations of long-acting bronchodilators and inhaled corticosteroids, on symptomatology, frequency and severity of acute 
exacerbations, quality of life, and survival in patients with COPD. ${ }^{23-26}$ Therefore, it could be argued that earlier pharmacological intervention than is currently practiced would produce even better outcomes. For this to be determined, early detection of COPD is key.

\section{Acknowledgements}

The authors would like to acknowledge the following members of the Primary Care Respiratory Working Group: Dr Stoney Abercrombie (Center for Family Medicine, Anderson, USA); Dr David Bellamy (James Fisher Medical Centre, Bournemouth, UK); Dr Jacques Bouchard (St Joseph's Hospital, La Malbaie, Canada); Dr Dominique Huas (22 Boulevard du General Leclerc, Nanterre, France); Dr Peter Kardos (Maingau Hospital, Frankfurt/Main, Germany); Dr Joseph Keenan (University of Minnesota, Minneapolis, USA).

\section{Conflict of interest}

This manuscript was funded by an educational grant from GlaxoSmithKline.

\section{References}

1. Global Initiative for Chronic Obstructive Lung Disease. NHLBI/WHO workshop report on Global Strategy for the Diagnosis, Management, and Prevention of Chronic Obstructive Pulmonary Disease. National Institutes of Health National Heart, Lung, and Blood Institute.

March 2001;Updated 2003. NIH Publication No 2701A (http://www.goldcopd.com; accessed July 31, 2003).

2. Barnes PJ. Chronic obstructive pulmonary disease. N Engl J Med 2000;343:269-80.

3. Agusti AGN, Noguera A, Sauleda J, Sala E, Pons J, Busquets X. Systemic effects of chronic obstructive pulmonary disease. Eur Respir J 2003;21:347-360. 4. World Health Report 1998. Life in the 21st Century: A vision for all. World Health Organization, Geneva, 1998.

5. Murray CJL, Lopez AD, Mathers CD, Stein C. The global burden of disease 2000 project: aims, methods and data sources. Global Programme on Evidence for Health Policy Discussion Paper No.36. World Health Organization, Nov 2001.

6. Murray CJL, Lopez AD. The global burden of disease: a comprehensive assessment of mortality and disability from diseases, injuries and risk factors in 1990, and projected to 2020. Harvard University Press: Cambridge MA 1996

7. U.S. Department of Commerce, Bureau of the Census. Statistical Abstract of the United States 1997. Washington (DC): Department of Commerce; 1997. 8. National Institutes of Health. National Heart, Lung and Blood Institute. Morbidity and Mortality: 2002 Chart Book on Cardiovascular, Lung and Blood Diseases. July 2003. (http://www.nhlbi.nih.gov; accessed July 31, 2003).

9. Strategies in preserving lung health and preventing COPD and associated diseases. The National Lung Health Education Program (NLHEP). Chest 1998;113:123S-163S.

10. Donaldson GC, Seemungal T, Jeffries DJ, Wedzicha JA. Effect of temperature on lung function and symptoms in chronic obstructive pulmonary disease. Eur Respir J 1999;13:844-9.
11. Seemungal TA, Donaldson GC, Paul EA, Bestall JC, Jeffries DJ, Wedzicha JA. Effect of exacerbation on quality of life in patients with chronic obstructive pulmonary disease. Am J Respir Crit Care Med 1998;157:1418-22.

12. Coultas DB, Mapel D, Gagnon R, Lydick E. The health impact of undiagnosed airflow obstruction in a national sample of United States adults. Am J Respir Crit Care Med 2001;164:372-7.

13. Enright PL, Crapo RO. Controversies in the use of spirometry for early recognition and diagnosis of chronic obstructive pulmonary disease in cigarette smokers. Clin Chest Med 2000;21:645-52.

14. Ferguson GT, Enright PL, Buist S, Higgins MW. Office spirometry for lung health assessment in adults. A consensus statement from the National Lung Health Education Program. Chest 2000;117:1146-61.

15. Law M, Tang JL. An analysis of the effectiveness of interventions intended to help people stop smoking. Arch Intern Med 1995;155:1933-1941.

16. Morris JF, Temple W. Spirometric 'lung age' estimation for motivating smoking cessation. Prev Med 1985;14:655-62.

17. Risser NL, Belcher DW. Adding spirometry, carbon monoxide and pulmonary symptom results to smoking cessation counseling: A randomized trial. J Gen Intern Med 1990; 5:16-22.

18. Hepper NG, Drage CW, Davies SF, et al. Chronic obstructive pulmonary disease: A community-oriented program including professional education and screening by a voluntary health agency. Am Rev Respir Dis 1980;121:97-104.

19. Fletcher C, Peto R. The natural history of chronic airflow obstruction. BMJ 1977;1:1645-8.

20. D'Urzo A. Differentiating asthma from COPD in primary care. Ont Thoracic Rev 2001;13:3-7. 21. Eaton T, Withy S, Garrett JE, Mercer J, Whitlock RML, Rea HH. Spirometry in primary care practice. The importance of quality assurance and the impact of spirometry workshops. Chest 1999;116:416-423. 22. Petty TL, Enright PL. Simple office spirometry for primary care practitioners. June 2003 (http://www.nlhep.org/resources.html\#phys; accessed July 31, 2003)

23. Paggiaro PL, Dahle R, Bakran I, Frith L, Hollingsworth K, Efthimiou J, on behalf of the International COPD Study Group. Multicentre randomised placebo-controlled trial of inhaled fluticasone propionate in patients with chronic obstructive pulmonary disease. The Lancet 1998;351:773-780.

24. Dompeling E, van Schayk CP, van Grunsven PM, et al. Slowing the deterioration of asthma and chronic obstructive pulmonary disease observed during bronchodilator therapy by adding inhaled corticosteroids. A 4-year prospective study. Ann Intern Med 1993;118:770-8.

25. Calverley PMA, Pauwels R, Vestbo J, et al. Combined salmeterol and fluticasone in the treatment of chronic obstructive pulmonary disease: A randomized controlled trial. The Lancet 2003; 361:449-56.

26. Soriano JB, Vestbo J, Pride NB, Kiri V, Maden C, Maier WC. Survival in COPD patients after regular use of fluticasone propionate and salmeterol in general practice. Eur Respir J 2002;20:819-25. 